Asian J Agric \& Biol. 2022(2).

$\mathrm{AJAB}$

DOI: $10.35495 / a j a b .2021 .03 .115$

Original Article

\title{
Nature and activities of microfungi associated with the decomposition of rice straw in Sri Lanka
}

\begin{abstract}
Lanka Undugoda ${ }^{1}$, Sagarika Kannangara ${ }^{2 *}$
${ }^{1}$ Department of Biosystems Technology, Faculty of Technology, University of Sri Jayewardenepura, Sri Lanka

${ }^{2}$ Department of Plant and Molecular Biology, Faculty of Science, University of Kelaniya, Sri Lanka

Received:

April 15, 2021

Accepted:

August 23, 2021

Online First:

November 03, 2021

Published:

February 28, 2022

Abstract

Agricultural sustainability through crop residue biodegradation is an eco-friendly method to enrich soil fertility essential to agricultural countries. Rice straw, rich in cellulose, is the primary source of organic matter, enhancing the fertility in rice fields and is a better alternative to replace chemical fertilizer usage. Therefore, this attempt is to isolate and identify different genera of straw degrading microfungi efficient in lignocellulose biodegradation. Rice straw degrading fungal species were isolated from the partially degraded rice straw collected from selected areas in Sri Lanka, following the washing and plating techniques. They were identified into the genus level using standard identification keys, and their capacity to degrade cellulose, starch, lignin, and pectin were evaluated using substrate-specific testing protocols. Eighteen fungal species in the genera of Aspergillus, Chaetomium, Cunninghamella, Goidanichiella, Penicillium, Rhizomucor, Rhizopus, Stachybotrys, and Trichoderma were isolated from the partially degraded rice straw collected from different areas of Sri Lanka. Three Trichoderma species showed significantly the highest frequency of occurrences $(40 \%, 45 \%$, and $43 \%$ respectively) in rice straw and a homogenous distribution among the collected samples. Furthermore, they were significantly efficient in degrading cellulose, starch, pectin, and lignin. Since the management of crop residues has become an essential aspect of sustaining long-term fertility in cropping systems, incorporation of rice straw, which is rich with cellulose, and the application of Trichoderma species into the harvested rice fields will improve the nutrient availability and hence rice yield.
\end{abstract}

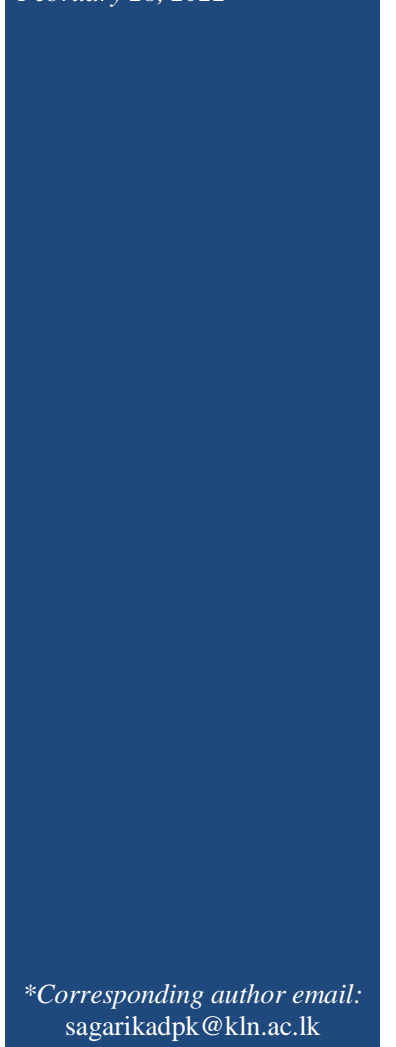

Keywords: Degradation, lignocellulose, rice straw, substrate utilization, Trichoderma spp.

\section{How to cite this:}

Undugoda L and Kannangara S, 2022. Nature and activities of microfungi associated with the decomposition of rice straw in Sri Lanka. Asian J. Agric. Biol. 2022(2): 202103115. DOI: https://doi.org/10.35495/ajab.2021.03.115

This is an Open Access article distributed under the terms of the Creative Commons Attribution 3.0 License. (https://creativecommons.org/licenses/by/3.0), which permits unrestricted use, distribution, and reproduction in any medium, provided the original work is properly cited.

\section{Introduction}

Interest in crop residue management and its influence on organic matter and nutrient cycling in soil have been increasing day by day due to the current demand for agricultural sustainability. Among many crop residues, rice straw is special in Sri Lanka as the most abundant agricultural byproduct rich with cellulose. Applying this main source of organic matter into the rice fields will enhance the fertility of rice fields and 
will be a better alternative to replace the chemical fertilizer usage in rice cultivation. However, the management of rice residue through the direct incorporation of straw into soil causes specific problems because of the slow decomposition and weak immobilization of plant nutrients due to its high cellulose, hemicellulose, silica, and lignin contents which make it difficult to degrade (Kumar et al., 2008; Schimpf et al., 2013; Li et al., 2017). Therefore, the application of partially decomposed rice straw is more suitable for maintaining sustainability in the rice fields than non-degraded raw rice straw (Goyal and Sindhu, 2011).

Microorganisms belonging to the groups of bacteria, fungi and actinomycetes are able to accelerate the decomposition rate of rice straw. Different microorganisms show different roles and capacities in the decomposition process as some microorganisms, including fungi, are able to degrade lignocellulose, and some can only degrade cellulose (Andlar et al., 2018). This variation depends on the enzyme production ability in their metabolism. Since cellulose and lignin are complex polysaccharides, only a few microorganisms have the potential in degrading such polymers into simple monomers, and an array of enzymes are responsible for this conversion. The enzymes which can break lignocellulose into stable compounds are called lignocellulolytic enzymes (Huai-Liang, 2010; Mohammad et al., 2013; Kumar and Chandra, 2020). Among microorganisms, fungi are the most efficient microorganisms that are able to carry out lignocellulolytic degradation of rice straw. The results of recent findings revealed that Fusarium sp., Aspergillus terreus, Paecilomyces fusisporous, Micromonospora sp., and Coriolusversicolor sp. have higher lignocellulolytic activities compared to the other tested microorganisms (Abdulla and ElShatourym, 2007; Goyal and Sindhu, 2011; Phutela and Sahni, 2012; Chen et al., 2019). In the present investigation, an attempt was given to isolate and identify rice straw degrading microfungi from the partially decomposed rice straw collected from the paddy fields in different Sri Lankan areas and then investigate their enzyme versatility in degrading pure substrates of lignin, cellulose, starch, and pectin. It was also hypothesized that the fungi isolated in a higher frequency of occurrences are efficient in depolymerizing pure substrates of cellulose and lignin, hence opening avenues for the possible application of those fungal genera to accelerate the decomposition of cellulose-rich rice straw.

\section{Material and Methods \\ Sample collection}

Partially decomposed rice straw samples (3.5 months after harvesting) were collected randomly from the paddy fields in Gampaha, Kurunegala, Anuradhapura, Kandy, and Hambanthota areas in Sri Lanka during the rainy season following the randomizing block design. Five random replicates were taken from the paddy fields in each area, and then they were transported to the University in sealed sterilized zip lock bags.

\section{Determination of the washing efficiency of partially degraded rice straw}

Twenty pieces $(1 \mathrm{~cm})$ were obtained randomly from each of the five replicate samples collected from each area with the help of a sharp blade. Then they were transferred into sterilized screw-capped bottles (100 $\mathrm{ml}$ capacity) containing $50 \mathrm{ml}$ sterilized distilled water and shaken at $300 \mathrm{rpm} / \mathrm{min}$ for two minutes. The water was then decanted into another series of sterilized bottles, and the process was repeated 30 times. One $\mathrm{mL}$ aliquot from the above water in each bottle was transferred to tubes containing molten agar (2\% malt extract agar) at $40{ }^{\circ} \mathrm{C}$, agitated by hand, poured into sterilized petri dishes, and incubated for four days at $30{ }^{\circ} \mathrm{C}$ (room temperature). Developed fungal colonies in the petri dishes were counted, and the relationship between the number of washings and the number of fungal colonies from each washing was evaluated.

\section{Isolation of fungi}

Fungal isolations were carried out following the modified Harley and Waid (1955) washing and plating technique. One gram of rice straw from each replicate sample was taken, and then it was cut into 1 $\mathrm{cm}$ pieces. Randomly selected twenty pieces $(1 \mathrm{~cm})$ from each replicate sample were transferred separately into $50 \mathrm{ml}$ sterilized water in $100 \mathrm{ml}$ screw-cap bottle and shaken at $300 \mathrm{rpm} / \mathrm{min}$ for 2 min using the shaker (Gyrotory shaker, model G2). This washing procedure was repeated eighteen times (as determined previously) to remove surface contaminants. Then excess water in the straw particles was wiped out using sterilized filter papers. Small pieces $(1 \mathrm{~mm} \times 1 \mathrm{~mm})$ of washed straw samples were plated on potato dextrose agar with streptomycin $(0.2$ $\mathrm{g} / \mathrm{L})$ and tetracycline $(0.05 \mathrm{~g} / \mathrm{L})$. Thirty pieces of straw 
from each of the five replicate samples collected from each area were plated and incubated at $28 \pm 2^{\circ} \mathrm{C}$ for 57 days. Growing fungi in the plated straw particles were isolated into pure cultures using a dissecting microscope (Olympus 313368).

\section{Identification of isolated fungi}

Colony morphological characteristics such as the color, shape, pigment production, and diameter of the isolated fungi were investigated by growing them in PDA (Potato dextrose agar) and 2\% MEA (Malt extract agar). The microscopic observations were done using the fungal specimens prepared following the sticky tape method (Flegel, 1980). Using all the characteristic features studied, they were identified into the genus level following online identification keys and other standard identification keys (Domsch et al., 1980; Barron, 1983). A further attempt was given to identify the isolated three species of Trichoderma into species level by comparing them with the available identified cultures of Trichoderma species (Trichoderma viride: AF218788.1, Trichoderma asperellum: KT588246.1, Trichoderma harzianum: KT852821.1, Trichoderma longibrachiatum KP132794.1, and Trichoderma virens: KP985643.1) in the Department of Plant and Molecular Biology, University of Kelaniya.

\section{Determination of frequency of occurrence of each fungus isolated from rice straw}

The percentage frequency of occurrence of fungi isolated from the rice straw particles of each of the replicate samples was calculated using the following equation.

\footnotetext{
Frequency of occurrence $(\%)=$ No of particles with the specific fungus $\frac{\text { No of particles with the specific fungus }}{\text { Total no. of particles plated }} \times 100$
}

(Visser and Parkinson, 1975; Kannangara et al., 2001; Kannangara and Deshappriya, 2005)

\section{Screening of substrate utilization capabilities of the isolated fungi}

The potential decomposer abilities and metabolic capabilities of individual fungi of partially decomposed rice straw were tested using the following pure substrates; starch, pectin, cellulose, and lignin (which represent plants' storage and structural components). The ability of the individual fungal species to utilize the above mentioned pure substrates was observed separately according to the procedures given below.

\section{Cellulose}

Cellulose agar medium was prepared with the addition of $1 \%$ cellulose powder into the basal medium of Eggins and Pugh (1961). These medium added test tubes were then inoculated separately with the isolated fungi and incubated at room temperature $\left(28 \pm 2^{\circ} \mathrm{C}\right)$ for a month or more until the cellulose utilization of the tested fungal species was visualized as clear zones.

\section{Starch}

As described by Kannangara (2002) and Kannangara et al., (2009) agar plates with 5\% starch were prepared. The plates inoculated separately with the isolated fungi were incubated at room temperature $\left(28 \pm 2^{\circ} \mathrm{C}\right)$ for five days. Then they were flooded with $1 \% \mathrm{~K}_{2}$ solution, and the amylolytic activity was investigated by the production of clear zones around the fungal colonies.

\section{Pectin}

Polygalacturanase and pectate lyase enzyme activities of the isolated fungal species were assessed using the modified basal medium of Eggins and Pugh (1961), as indicated in Kannangara et al. (2009). Two sets of plates were prepared separately to check two enzyme activities by changing the $\mathrm{pH}$ to $\mathrm{pH} 5$ (polygalacturanase activity) and $\mathrm{pH} 7$ (pectate lyase activity). After a 5-7 days incubation period at $22{ }^{\circ} \mathrm{C}$, all the plates were flooded with $1 \%$ cetavlon solution (Cetyl trimethyl ammonium bromide). Pectin utilization was indicated by the formation of clear zones around the active colonies.

\section{Lignin}

The fungal species were tested for the production of three enzymes, laccases, peroxidase, and tyrosinase, involved in the depolymerization of lignin by growing them separately on $2 \%$ malt extract agar at pH 7 (Kannangara et al., 2009). After a 5-7 days incubation period at $22{ }^{\circ} \mathrm{C}$, drop tests were carried out to observe the production of each of the three enzymes responsible for the lignin breakdown in plant tissue, as indicated in Kannangara et al. (2009).

\section{Statistical analysis}

Data analysis was done using SPSS software package version 17.0. The method introduced by Snedecor 
and Cochran (1980) was used to analyze the data. The level of significance was set at $\mathrm{P}<0.05$.

\section{Results and Discussion}

\section{Fungal isolation}

Figure. 1 indicates the results obtained from the experiments conducted to investigate the washing efficiency of partially decomposed rice straw. The detachable fungal fragments that develop into a mycelium rapidly declined from the first washing sample to the seventh washing sample. Eventually, the partially degraded straw samples were gradually cleaned until a low, fairly constant number was displaced in the fifteenth to twenty-first washings. After the twenty-first washing, recolonization ability of the number of the detachable fungal fragment was gradually increased. Therefore, eighteenth washing was taken as the optimum number of washing required to eliminate the surface contaminants from the partially decomposed rice straw.

Serial washing of straw material in sterile water before plating was required to eliminate the surface contaminants of the rice straw. The results of Harley and Waid (1955) revealed that washing techniques give a chance to isolate diverse surface fungal flora of spore derived fungi, mycelium derived fungi, and sterile fungi compared to the diluted plate method and plating unwashed fragments. A minimum number of washings required to eliminate the surface contaminants is called washing efficiency. When the materials were serially washed, surface contaminants (detachable fungal fragments) were gradually removed from the litter. However, if it was done indefinitely, tissue could be damaged, and active fungal fragments colonizing inside the tissue could come out, and they would be removed with decanting water. Therefore, the straw material should be gradually cleaned until a low fairly constant number of fungal colonies are displaced. A fairly constant number of colonies were displaced in the present study for fifteen to twenty first washing. After the twenty first washing, the number of fungal colonies increases again due to the detachment of active fungal fragments inside the tissue of rice straw.

\section{Frequency of occurrences of isolated fungal species}

Eighteen fungal species belonging to the genera of Aspergillus, Chaetomium, Cunninghamella,
Goidanichiella, Penicillium, Rhizomucor, Rhizopus, Stachybotrys, and Trichoderma were isolated from the partially decomposed rice straw which was aged for three and half months. Out of these isolates, Trichoderma species (T. viride, T. harzianum, and T.asperellum) showed significantly the highest (40 $\%, 45 \%$, and $43 \%$ respectively), frequency of occurrences in partially decomposed rice straw. Out of other isolated fungal species, Cunningamela sp., Penicillium sp. 1, Penicillium sp.2, and Goidanichiella sp. had a comparatively higher frequency of occurrences as $30 \%, 23 \%, 13 \%$, and $13 \%$, respectively. Chaetomium sp.2, Stachybotrys sp. and dark sterile sp. showed the lowest frequency of occurrences $(3 \%, 2 \%$, and $2 \%$, respectively) in the decomposed rice straw. All these results revealed that $T$. viride, $T$. harzianum, $T$. asperellum, Cunningamela sp., Penicillium sp. 1, Penicillium sp.2, and Goidanichiella sp. were the dominant fungal species involved in the decomposition of rice straw in the paddy fields in the selected areas in Sri Lanka (Figure. 2).

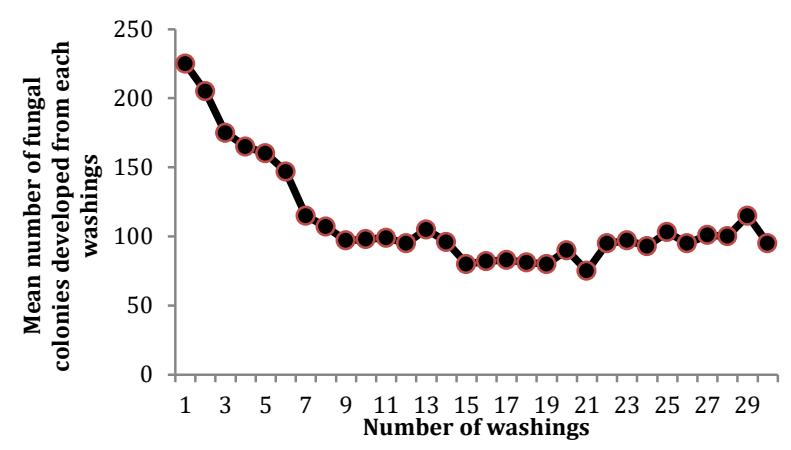

Figure-1: Mean number of fungal colonies washed off from partially decomposed rice straw shaken in aliquots of sterile water. (Each data point represents the mean of five replicates)

As per the results of Sangjoon et al. (2011), the fungal species (A. versicolor KUC5201, A. ochraceus KUC5204, Aspergillus niger KUC5183, Trichoderma harzianum 1 KUC5182, Mucor circinelloides KUC6014, and an unknown basidiomycetes species, KUC8721) isolated from the post-harvest rice straw collected from the eleven different sites in Korea have shown a higher frequency of occurrences. Trichoderma harzianum 1 KUC5182 was identified as the best cellulose degrader with the highest frequency of occurrence. Robinson (1994) reported the occurrence of Trichoderma spp. at higher frequencies in wheat and corn residues. Aspergillus 
sp. and Chaetomium sp. used in the composting process in Japan were isolated at higher frequencies of occurrences from composting paddy straw (Cahyani et al., 2004). Moreover, Humicola sp. (Th10), Aspergillus nidulans (Th4), and Scytalidium thermophilum (Th5), were isolated at a higher frequency of occurrences from the wheat straw samples collected from Indian Agricultural Research Institute (IARI) Farm, yard manure, and soil (Kumar et al., 2008).

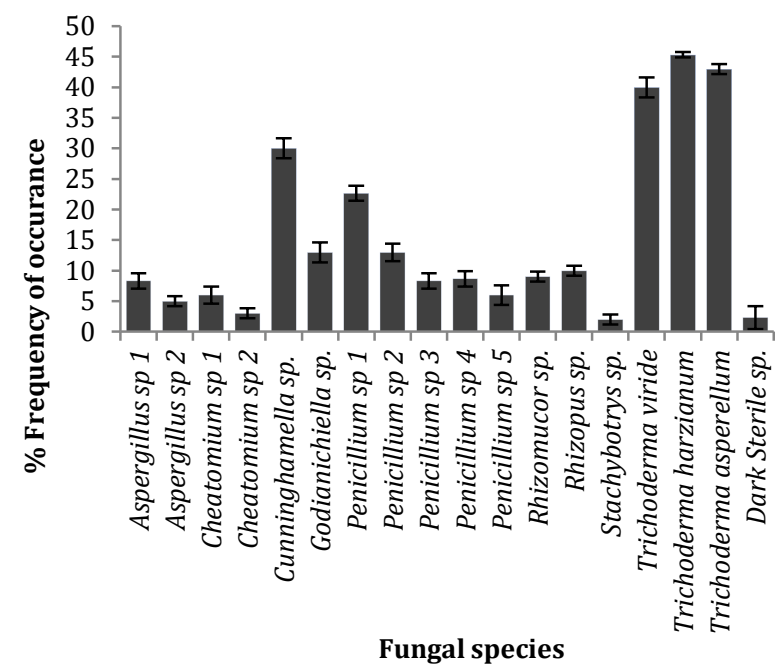

Figure-2: Percentage frequency of occurrences of the fungal species isolated from partially decomposed rice straw $(\mathbf{n}=5)$.

\section{Distribution patterns of fungi in decomposing rice straw}

Figure. 3 shows the distribution patterns of each fungus in the decomposed straw samples collected from paddy fields of different areas in Sri Lanka. All the isolated three Trichoderma species showed a homogeneous distribution in all the collected samples indicating their abundance at higher frequencies within the country. Stachybotrys sp. and dark sterile sp. had the lowest frequency of occurrences, showed heterogeneous distribution patterns in the collected decomposed rice straw samples. In agreement with Sangjoon et al. (2011), the results of the present investigation revealed a correlation between the frequency of occurrence and the distribution of the fungal species in partially decomposed rice straw collected from different areas of Sri Lanka at $\mathrm{p}<0.05$. The investigation carried out by Sangjoon et al. (2011), showed significantly higher occurrences of Aspergillus niger, Alternaria alternata, Dothideomycete sp., Nigrospora oryzae, Curvularia intermedia, and Cladosporium sp., almost in all the samples collected from the selected areas in Korea.

\section{Substrate utilization capabilities of the isolated fungi}

Fungi are able to secrete various types of hydrolytic and oxidative enzymes to degrade various polysaccharides such as cellulose, hemicellulose, and pectin (Abd-Elzaher and Fadel, 2010). The results of the investigations on pure non-labile complex carbohydrate utilization capabilities of isolated fungi revealed, all the eighteen fungal species had cellulose degrading capabilities, and only some of them showed the capability in lignin, pectin, and starch degradation (Table. 1).

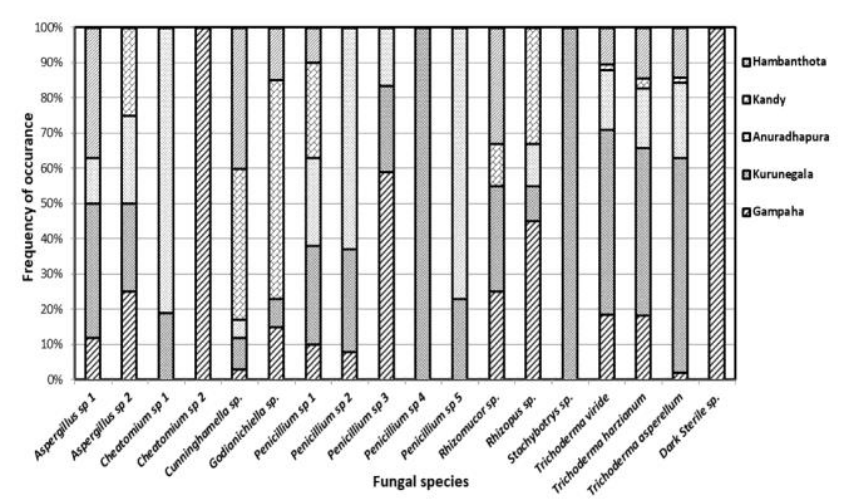

Figure-3: Distribution of the fungal species isolated from partially decomposed rice straw in different areas of Sri Lanka $(n=5)$

\section{Utilization of cellulose}

T. harzianum, T. viride, and T. asperellum, isolated at the highest frequency of occurrence, were significantly more efficient in degrading cellulose than the other tested fungal species. This was demonstrated by the well-marked clear zones in the test tubes containing cellulose agar (Figure. 4A). These results agreed with the findings of Sangjoon et al. (2011), in which Trichoderma harzianum 1 KUC5182 isolated from the post-harvested rice straw collected from eleven different sites in Korea showed the highest cellulolytic and xylanolytic activities. Furthermore, the findings of Bakar et al. (2018), revealed that Trichoderma species were able to degrade rice straw due to their high cellulolytic activity. The results of Jorgensen and Olsson (2006); Li et al. (2017) revealed that several Penicillium species were able to produce cellulolytic enzymes. The findings of Krogh et al. (2004) showed that twelve filamentous fungi from the genus Penicillium 
were able to produce cellulolytic and xylanolytic enzymes. All five Penicillium species isolated in the present study also indicated the ability to degrade cellulose. Microbial degradation of cellulose is carried out by an array of cellulase enzymes collectively known as endoglucanases, exocellulases, and processive endoglucanases. Gautam et al. (2011), have tested the production of cellulases by A.niger and Trichoderma sp. during the decomposition process of municipal solid waste, and the results revealed that Trichoderma sp. secreted endoglucanase $(1.95 \mathrm{U} / \mathrm{mL})$, exoglucanase $(1.77$ $\mathrm{U} / \mathrm{mL})$, and $\beta$-glucosidase $(1.66 \mathrm{U} / \mathrm{mL})$ in high levels during the municipal waste decomposition compared to A.niger.

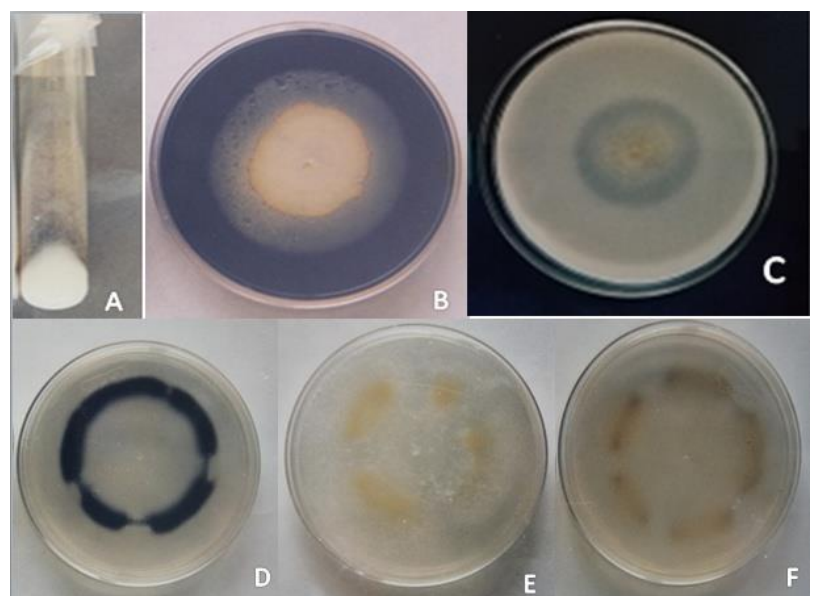

Figure-4: Substrate utilization capabilities of the fungi isolated from partially decomposed rice straw

(A) Cellulase activity of Trichoderma sp. visualized as clear zones of hydrolysis, (B) Amylase activity of Trichoderma viride visualized as clear zones of hydrolysis, (C) Polygalacturanase activity of Trichoderma viride visualized as clear zones of hydrolysis, (D) Diffusion of purplish coloration into the medium indicated the laccase activity of Trichoderma viride, (E) Yellow brownish coloration indicated the production of peroxidases by Trichoderma harzianum, (F) Diffusion of orange brown colour into the medium indicated the presence of tyrosinase enzyme in the plates containing Trichoderma harzianum.

\section{Starch utilization}

In the present study, only ten fungal species ( $T$. viride, T. harzianum, T. asperellum, Aspergillus sp.1, Penicillium sp. 1, 2, 3, 4, 5, and dark sterile species) were able to decompose starch (Table 1). Fungal enzymes responsible for degrading starch and glycogen are $\infty$-amylase, amyloglucosidase, $\infty$ glucosidase, isoamylase, and phosphorylase. Probably $\infty$-amylase is the most widely distributed enzyme, and it hydrolyses $\infty-1,4$ linkages in the starch polymer (Cooke and Whipps, 1993). The findings of Fioretto et al. (2001) revealed that $\infty$ amylase and, to a lesser extent, $\beta$-amylase activities occurred at the highest level during the initial stages of decomposition. However, the present findings revealed that three Trichoderma spp., Aspergillus sp.1, Penicillium sp. 1, 2, 3, 4, 5, and dark sterile species were able to utilize starch even though they have been isolated from the three months old rice straw. This was shown by the clear zones around the fungal colonies after flooding with KI/I2 solution that indicated the amylase activity (Figure. 4B).

\section{Pectin utilization}

Eleven fungal species showed the pectin degradation capability by indicating clear zones on the plates prepared using the basal medium of Eggins and Pugh (1961) and $0.5 \%$ of liquid citrus pectin. Polygalacturonase activity was shown when the medium $\mathrm{pH}$ was adjusted to $\mathrm{pH} 5$ (Figure.4C). Pectate lyase activity was shown by $T$. viride, $T$. harzianum, T. asperellum, Aspergillus sp.1, Aspergillus sp.2, Cunninghamella sp. Penicillium sp.1, Penicillium sp.3, Penicillium sp.4, Penicillium sp.5, and Rhizomucor sp. at $\mathrm{pH}$ 7. All the three Trichoderma species produced significantly larger clear zones indicating their efficiencies in polygalacturanase and pectate lyase activities. According to the findings of Zeni et al. (2011), Aspergillus niger ATCC and Penicillium sp. isolated from agro-industrial areas were able to produce polygalacturonases in pectin degradation. In agreement with that, in the present study, two Aspergillus species and four Penicillium species isolated from rice, straw were able to degrade pectin via secreting both polygalatuonase and pectate lyase. However, all the three Trichoderma species tested were also able to degrade pectin efficiently with the aid of polygalacturonase and pectate lyase enzymes compared to other isolated fungal species.

\section{Lignin utilization}

Evaluation of lignin utilization potentials of the tested fungi revealed that ten fungal species were able to produce at least one, two, or three enzymes involved in lignin degradation. Out of them, seven fungal 
species (Chaetomium sp.1, Chaetomium sp.2, Penicillium sp.5, Stachybotrys sp., $T$. viride, $T$. harzianum and T. asperellum) were able to produce only laccase and peroxidase (Table.1). However, $T$. harzianum and T.asperellum were significantly efficient in producing all the three enzymes laccase (Figure. 4D), peroxidase (Figure. 4E), and tyrosinase (Figure. 4F), indicating their potential in degrading lignin which is a rigid polymer in plants and has the potential for very selective depolymerization. The research findings of Bakar et al. (2018) have also shown the potential in Trichoderma spp. to degrade lignin in paddy straw.

Table-1: Substrate utilization potential of fungi isolated from partially decomposed rice straw

\begin{tabular}{|c|c|c|c|c|c|c|c|c|}
\hline \multirow{2}{*}{$\begin{array}{l}\text { Fungal } \\
\text { species }\end{array}$} & \multirow{2}{*}{ Cellulose } & \multirow{2}{*}{ CMC } & \multirow{2}{*}{ Starch } & \multicolumn{2}{|c|}{ Pectin } & \multicolumn{3}{|c|}{ Lignin } \\
\hline & & & & PO & PC & LA & $\mathbf{P E}$ & TY \\
\hline $\begin{array}{l}\text { Aspergillus } \\
\text { sp.1 }\end{array}$ & + & + & + & + & + & - & - & - \\
\hline $\begin{array}{l}\text { Aspergillus } \\
\text { sp.2 }\end{array}$ & + & + & - & + & + & - & - & - \\
\hline $\begin{array}{l}\text { Chaetomium } \\
\text { sp.1 }\end{array}$ & + & + & - & - & - & + & + & - \\
\hline $\begin{array}{l}\text { Chaetomium } \\
\text { sp.2 }\end{array}$ & + & + & - & - & - & + & + & - \\
\hline $\begin{array}{l}\text { Cunninghame } \\
\text { lla sp. }\end{array}$ & + & - & - & + & + & - & - & - \\
\hline $\begin{array}{l}\text { Goidanichiell } \\
a \text { sp. }\end{array}$ & + & + & - & - & - & - & - & - \\
\hline $\begin{array}{l}\text { Penicillium } \\
\text { sp.1 }\end{array}$ & + & + & + & + & + & - & - & - \\
\hline $\begin{array}{l}\text { Penicillium } \\
\text { sp.2 }\end{array}$ & + & + & + & - & - & - & + & - \\
\hline $\begin{array}{l}\text { Penicillium } \\
\text { sp.3 }\end{array}$ & + & + & + & + & + & - & + & - \\
\hline $\begin{array}{l}\text { Penicillium } \\
\text { sp.4 }\end{array}$ & + & + & + & + & + & - & - & - \\
\hline $\begin{array}{l}\text { Penicillium } \\
\text { sp.5 }\end{array}$ & + & + & + & + & + & + & + & - \\
\hline $\begin{array}{l}\text { Rhizomucor } \\
\text { sp. }\end{array}$ & + & - & - & + & + & - & - & - \\
\hline Rhizopus sp. & + & + & - & - & - & - & + & + \\
\hline $\begin{array}{l}\text { Stachybotrys } \\
\text { sp. }\end{array}$ & + & + & - & - & - & + & + & - \\
\hline T. viride & + & + & + & + & + & + & + & - \\
\hline T. harzianum & + & + & + & + & + & + & + & + \\
\hline $\begin{array}{l}\text { Trichoderma } \\
\text { asperellum }\end{array}$ & + & + & + & + & + & + & + & + \\
\hline $\begin{array}{l}\text { Dark sterile } \\
\text { sp. }\end{array}$ & + & + & + & - & - & - & - & - \\
\hline
\end{tabular}

Even though many researchers have reported the ability of different Rhizopus species in degrading specifically pectin (Odeniyi et al., 2009), in the present study, the tested Rhizopus species were able to degrade cellulose and lignin only by secreting, peroxidase and tyrosinase. In Penicillium spp., the tested two species were able to produce only peroxidases in contrast to Choudhary et al. (2016). They have investigated the potential in Penicillium pinophilum isolated from wheat straw harvested soil to degrade lignin through the laccase activity. In the present study, only $T$. harzianum and T.asperellum were able to produce the three enzymes laccase, peroxidase, and tyrosinase necessary to degrade lignin and all the other tested pure substrates.

All in all, out of the eighteen fungal species isolated from the three months aged paddy straw, Trichoderma species showed the best cellulases, amylases, laccase, peroxidase, tyrosinase (except T.viride) polygalacturonases, and pectate lyases activities compared to the other isolated fungal species. Chemical fertilizer application to rice cultivation in Sri Lanka was carried out widely with high yielding rice varieties for more than four decades. The findings of Yan et al., 2019 revealed that the application of rice straw into the paddy fields at the recommendation rate of four tons per hectare is good enough to provide the total potassium requirement, phosphorus requirement, and $30 \%$ of the nitrogen requirement of the rice crop. As per the investigation carried out by Ponnamperuma (1984), rice straw consists of $\mathrm{N}(0.38-1.01 \%), \mathrm{P}(0.01-$ $0.12 \%)$, and K (1.0-3.0\%). Unfortunately, most Sri Lankan farmers used to burn or remove the rice straw after the harvesting, and this permanent removal of straw material is an excellent nutrient loss to the paddy fields. This is entirely due to farmers' lack of awareness about the in situ use of rice straw as a nutritional enrichment source in paddy fields (Melissa et al., 2016).

Due to the inconvenience of harrowing and plowing the field in the presence of fresh straw, many farmers in Sri Lanka do not practice the process of recycling rice straw in the field. On the other hand, rice straw decomposition is prolonged due to its high lignin and cellulose contents. This problem could be overcome by accelerating the decomposition of rice straw by introducing indigenous microorganisms efficient in degrading cellulose and lignin into the paddy fields on large scales. However, the research findings of the present investigation highlighted that Trichoderma species (T. viride, T. harzianum, and T.asperellum) which were isolated significantly in higher frequencies $(40 \%, 45 \%$, and $43 \%$ respectively) from partially decomposed rice straw were efficient in 


\section{Lanka Undugoda and Sagarika Kannangara}

degrading all the pure substrates tested (cellulose, starch, lignin, and pectin) and also were efficient in secreting laccase, peroxidase, and tyrosinase (except T.viride) which are the most responsible enzyme in the degradation of lignin. These findings will open the avenues for possible application of our indigenous Trichoderma species into the rice fields in Sri Lanka to overcome the problem associated with the slow decomposition of rice straw and the return of $\mathrm{P}, \mathrm{K}$, and $\mathrm{N}$ back into the soils.

\section{Conclusion}

Out of the eighteen fungal species isolated from partially decomposed rice straw, Trichoderma isolates ( $T$. harzianum, T.asperellum, and $T$ viride) had the highest frequency of occurrences in the washed rice straw particles. The results of the enzyme activity experiments revealed higher efficiencies of Trichoderma species in degrading plant structural and storage compounds. T. harzianum was highlighted as the most efficient fungus in utilizing all the pure, tested substrates (cellulose, starch, lignin, and pectin) and were more efficient in secreting ligninolytic enzymes such as laccase, peroxidase, and tyrosinase. Since the higher amounts of cellulose and lignin contents are the causative factors for the slow decomposition of lignocellulosic rice straw, the present investigation indicates the possibility to accelerate the in situ biodegradation of rice straw left in the paddy fields after harvesting through the incorporation of indigenous Trichoderma species.

\section{Acknowledgement}

The authors wish to thank Prof. Bimali Jayawardena, Department of Chemistry, Faculty of Science, University of Kelaniya, for her assistance in improving this manuscript.

\section{Disclaimer: None.}

Conflict of Interest: None.

\section{Source of Funding: None.}

\section{References}

Abd-Elzaher FH and Fadel M, 2010. Production of bioethanol via enzymatic saccharification of rice straw by cellulase produced by Trichoderma reesei under solid state fermentation. New York Sci. 3(4): 72-78.

Abdulla HM and El-Shatourym SA, 2007. Actinomycetes in rice straw decomposition. J. Waste Manage. 27(6): 850-853.

Andlar M, Rezic T, Mardetko N, Kracher D, Ludwig R and Santek B, 2018. Lignocellulose degradation: An overview of fungi and fungal enzymes involved in lignocellulose degradation. Eng. Life Sci.18(11): 768-778.

Bakar NAA, Rahman MHA, Shakri NA, Bakar SA and Hamid AA, 2018. Preliminary study on rice straw degradation using microbial inoculant under shake flask condition. Afr. J. Biotechnol. 17(49): 13771382.

Barron GL, 1983. A new Amoebophilus (Zygomycetes) ectoparasitic on amoebae. Can. J. Bot. 61(12): 30913094.

Cahyani VR, Matsuya K, Asakawa S and Kimura M, 2004. Succession and phylogenetic profile of eukaryotic communities in the composting process of rice straw estimated by PCR-DGGE analysis. Biol. Fertil. Soils. 40(5): 334-344.

Chen KJ, Tang JC, Xu BH, Lan SL and Cao Y, 2019. Degradation enhancement of rice straw by co-culture of Phanerochaete chrysosporium and Trichoderma viride. Sci. Rep. 9: 19708.

Choudhary M, Sharma PC, Jat HS, Nehra V, McDonald AJ and Garg N, 2016. Crop residue degradation by fungi isolated from conservation agriculture fields under rice-wheat system of North-West India. Int. J. Recycl. Org. Waste Agric. 5(4): 349-360.

Cooke RC and Whipps JM, 1993. Ecophysiology of fungi, Blackwell Sci Publ., London.

Domsch KM, Gams W and Anderson TH, 1980. Compendium of soil fungi. Academic Press Inc, New York. pp. 1-859.

Eggins HOW and Pugh GJF, 1961. Isolation of cellulosedecomposing fungi from the soil. Nature. 193(4810): 94-95.

Fioretto A, Papa S, Sorrentino G and Fuggi A, 2001. Decomposition of Cistus incanus leaf litter in a Mediterranean maquis ecosystem: mass loss, microbial enzyme activities and nutrient changes. Soil Biol. Biochem. 33(3): 311-321.

Flegel TW, 1980. Semi-permanent microscope slides of microfungi using a sticky tape technique. Canad. J. Bot. 26(4): 551-553.

Gautam SP, Bundela PS, Pandey AK, Khan J and Sarsaiya AS, 2011. Optimization for the production of cellulase enzyme from municipal solid waste residue by two novel cellulolytic fungi. Int. J. Biotechnol. Res. 20: 8. 


\section{Lanka Undugoda and Sagarika Kannangara}

Goyal S and Sindhu SS, 2011. Composting of rice straw using different inocula and analysis of compost quality. Microbiol. J. 4: 123-138.

Harley JL and Waid JS, 1955. A method of studying active mycelia on living roots and other surfaces in the soil. Transact. Brit. Mycol. Soc. 38(2): 104-118.

Huai-Liang MA, 2010. Research on partial enzymological property of crude cellulase and xylanase from three kinds of edible fungus residues. J. Anhui. Agric. Sci. 28: 15.

Jorgensen $\mathrm{H}$ and Olsson L, 2006. Production of cellulases by Penicillium brasilianum IBT 20888Effect of substrate on hydrolytic performance. Enzyme Microb. Technol. 38(3-4): 381-390.

Li P, Li Y, Zheng X, Ding L, Ming F, Pan A, Lv W and Tang X, 2017. Rice straw decomposition affects diversity and dynamics of soil fungal community but not bacteria. J. Soil. Sediment. 18: 248-258.

Kannangara BTSDP, 2002. Microbial leaf characteristics of fast decomposing leaf litter at the upper mountain rainforest, Sri Lanka. Ph.D. Dissertation, University of Kelaniya, Kelaniya.

Kannangara BTSDP, Deshappriya N and Parkinson D, 2001. Fungal succession on Michelia nilagirica and Semecarpus coriacea leaf litter. Trop. Agric. Res. 13: 13- 22.

Kannangara BTSDP and Deshappriya N, 2005. Microfungi associated with leaf litter decomposition of Michelia nilagirica and Semecarpus coriacea at Hakgala montane forest. J. Natl. Sci. Found. 33(2): 81-91.

Kannangara BTSDP, Rajapaksha RSCG and Paranagama PA, 2009. Nature and bioactivities of endolichenic fungi in Pseudocyphellaria sp., Parmotrema sp. and Usnea sp. at Hakgala montane forest in Sri Lanka. Lett. Appl. Microbiol. 48(2): 203-209.

Krogh KB, Morkeberg A, Jorgensen H, Frisvad JC and Olsson L, 2004. Screening genus Penicillium for producers of cellulolytic and xylanolytic enzymes. pp. 389-401. In Proceedings, 25th Symposium on Biotechnology for Fuels and Chemicals, 4-7 May 2003, Breckenridge, CO. Humana Press, Totowa, NJ.

Kumar AS, Gaind and Nain L, 2008. Evaluation of thermophilic fungal consortium for paddy straw composting. Biodegradation. 19: 395-402.

Kumar A and Chandra R, 2020, Ligninolytic enzymes and its mechanisms for degradation of lignocellulosic waste in environment. Heliyon. 6: e03170.

https://doi.org/10.1016/j.heliyon.2020.e03170

Melissa MA, Bobbi LH and Reynald LL, 2016. Microbial crop residue decomposition dynamics in organic and conventionally managed soils. Appl. Soil Ecol.107: 347-359.

Mohammad HAR, Ong HK, Nurul AB and Fauzi J, 2013. Application of agro-waste compositional data to predict composting efficiency. J. Trop. Agric. Food Sci. 41(2): 329-339.

Odeniyi OA, Onilude AA and Ayodele MA, 2009. Production characteristics and properties of endoglucanase/polygalacturonase by a Bacillus coagulans strain from a fermenting palm-fruit industrial residue. Afr. J. Microbiol. Res. 3(8): 407417.

Phutela UG and Sahni N, 2012. Effect of Fusarium sp. on paddy straw digestibility and biogas production. J. Adv. Lab. 3(1): 9-12.

Ponnamperuma FN, 1984. Straw as a source of nutrients for wetland rice. In Organic matter and rice. Int. Rice Res. 34: 117-136.

Robinson D, 1994. The response of plants to non-uniform supplies of nutrients. New Phytol. 127: 635-674.

Sangjoon LYS, Lee YM, Lee JJ, Lee HB, Kim GH and Kim JJ, 2011. Rice straw-decomposing fungi and their cellulolytic and xylanolytic enzymes. J. Microb. Biotechnol. 21(12): 1322-1329.

Schimpf U, Hanreich A, Mähnert P, Unmack T, Junne S, Renpenning J and Lopez Ulibarri R, 2013. Improving the efficiency of large-scale biogas processes: pectinolytic enzymes accelerate the lignocellulose degradation. J. Sustain. Energy Environ. 4(53): 53-60.

Snedecor GW and Cochran WG, 1980. Statistical Methods, 7th ed. Iowa State University Press, Ames.

Visser S and Parkinson D, 1975. Fungal succession on aspen poplar leaf litter. Canad. J. Bot. 53(16): 16401651.

Yan C, Yan SS, Jia TY, Dong SK, Ma CM and Gong ZP, 2019. Decomposition characteristics of rice straw returned to the soil in northeast China. Nutr. Cycl. Agroecosyst. 114:211-224.

\section{Contribution of Authors}

Both Undugoda L and Kannangara $\mathrm{S}$ equally contributed in this article.

Zeni J, Cence K, Grando CE, Tiggermann L, Colet R, Lerin LA, Cansian RL, Toniazzo G, De Oliveira D and Valduga E, 2011. Screening of pectinaseproducing microorganisms with polygalacturonase activity. Appl. Biochem. Biotechnol. 163(3): 383-392. 